\title{
Microbial and operational response of an anaerobic fixed bed digester to oleic acid overloads
}

\author{
A.J. Cavaleiro, M.M. Alves *, M. Mota \\ Centro de Engenharia Biologica, IBQF, Universidade do Minho, Campus de Gualtar 4710-057 Braga, Portugal
}

Received 24 January 2001; received in revised form 23 April 2001; accepted 23 May 2001

\begin{abstract}
The effect of oleic acid overloads on biomass accumulation and activity in an anaerobic filter was investigated. An anaerobic fixed-bed reactor specially designed to allow the regular withdrawal of accumulated biomass was used for that purpose. Organic and hydraulic shocks were performed during four days, by stepwise increasing the substrate concentration from 4000 to 20000 $\mathrm{mg} \mathrm{COD} / 1$ or by reducing the hydraulic retention time from 16 to $3.2 \mathrm{~h}$. During the organic shock, operational performance was more affected than in the hydraulic one, which was the result of the higher degree of inhibition detected in the acetoclastic, hydrogenophilic and syntrophic activities. The ratio adhered/total biomass remained between 17 and $32 \%$ during the hydraulic shock, and between 13 and $60 \%$ during the organic shock, suggesting a more stable biofilm during the hydraulic shock. A long time $(900 \mathrm{~h})$ after the hydraulic shock, hydrogenophilic and syntrophic activities recovered to higher values than before the shock, but after the organic shock only acetoclastic activity recovered pre-shock values. Hydraulic shock induced an increase in tolerance to oleic acid toxicity, evidenced by an increase in the toxicity limit $\left(\mathrm{IC}_{50}\right)$ from $140 \pm 30$ to $215 \pm 25 \mathrm{mg} / 1$. C) 2001 Elsevier Science Ltd. All rights reserved.
\end{abstract}

Keywords: Anaerobic filters; Long-chain fatty acids; Methanogenic activity; Oleic acid toxicity; Shocks

\section{Introduction}

Anaerobic digestion technology has evolved quickly in the last decades and the modern high rate anaerobic digesters can compete advantageously with aerobic systems for treating industrial wastewater. However, the slower growth rate of anaerobic bacteria when compared to aerobes determines that anaerobic digesters should operate with cell retention times far greater (4-10 fold) than those used in aerobic processes. As a result, every disturbance to normal biomass growth will be more harmful and the recovery from shock will be longer in anaerobic processes, with the natural consequences of malfunctioning for the wastewater treatment system. Therefore it is of utmost importance to deepen the current knowledge on the dynamic growth of some key trophic groups in the anaerobic consortium during

\footnotetext{
* Corresponding author. Tel.: + 351-253-604-402; fax: + 351-253678-986

E-mail address: madalena.alves@deb.uminho.pt (M.M. Alves).
}

transient conditions, identifying the more affected ones. Such a better knowledge can contribute to the development of appropriate modifications in design and operation that can lead to general improvements in the stability of the anaerobic system.

Lipids are one of the major components of organic matter in wastewater and are easily hydrolysed to Long Chain Fatty Acids (LCFA), which are further converted to acetate and hydrogen through a $\beta$-oxidation mechanism by the proton reducing acetogenic bacteria [1]. The two main problems associated with the anaerobic treatment of lipid containing wastewaters are: (i) the adsorption of a lipid layer around biomass particles causing biomass flotation and washout and (ii) the acute toxicity of LCFA against both methanogens and acetogens, the two main groups involved in LCFA degradation [2,3]. In UASB reactors, sludge flotation occurs at concentrations far below the toxicity limit, which might suggest that complete washout of granular sludge would occur prior to inhibition [4]. Furthermore, addition of calcium salts prevents inhibition to some extent, but does not prevent flotation [2]. 
During organic and hydraulic shocks, the treatment performance generally deteriorates, often resulting in process souring and failure. Removal efficiency, methane concentration in the biogas and $\mathrm{pH}$ decrease, whereas volatile fatty acids (VFA) accumulate in the effluent. Massive sloughing of biofilm from the support medium and washout of the biomass from the reactor are common under unfavourable conditions that cause inhibition to the microorganisms or excessive hydraulic shear to the biofilm $[5,6]$. A shock load of LCFA can make a reactor inactive for long periods [7].

In the anaerobic fixed bed digester or anaerobic filter, biomass is entrapped in the void space and adhered to the surface of a support matrix. A lower risk of biomass flotation and washout is predictable in this type of reactor when compared to sludge bed systems such as UASB reactors. In the upflow mode, the adhered biomass usually plays a minor role due to its low proportion as compared to the total accumulated biomass. However, depending on support properties such as bed and carrier porosity, surface area, and type of material, a thick biofilm can be formed increasing its importance on the overall performance [8]. Furthermore if hydraulic or toxic shocks are applied, the adhered biomass provides a more stable immobilization than the entrapped one. One of the most serious problems associated with the study of anaerobic filters is the difficulty of determining biomass quantity and quality as well as their evolution with time and operating conditions.

In a previous work, a new anaerobic fixed-bed reactor configuration that allowed the regular withdrawal of accumulated biomass with minimum operation disturbances was presented [9]. The application of this new methodology to the effect of lipids and oleic acid on biomass development under steady state conditions, led to the conclusion that the biofilm formed in the presence of lipids was thinner, but more resistant to the presence of oleic acid than the biofilm formed in the absence of lipids [10]. During long term operation, the tolerance to toxicity and the biodegradability of oleic acid were improved by acclimatization with lipids or oleate below a threshold concentration [11].

In the present work the study is focused on the effect of oleic acid under load shock conditions. The biomass is characterized in terms of distribution between adhered and entrapped fractions, methanogenic activity of several key trophic groups in the anaerobic consortium such as syntrophic, acetoclastic and hydrogenotrophic bacteria. An organic and a hydraulic shock were applied and the tolerance to oleic acid toxicity was also assessed before and after each shock. Oleic acid was used as a model for LCFA because it is in general the most abundant of all LCFA present in wastewater [12], has a good solubility and it is recognized as one of the more toxic LCFA.

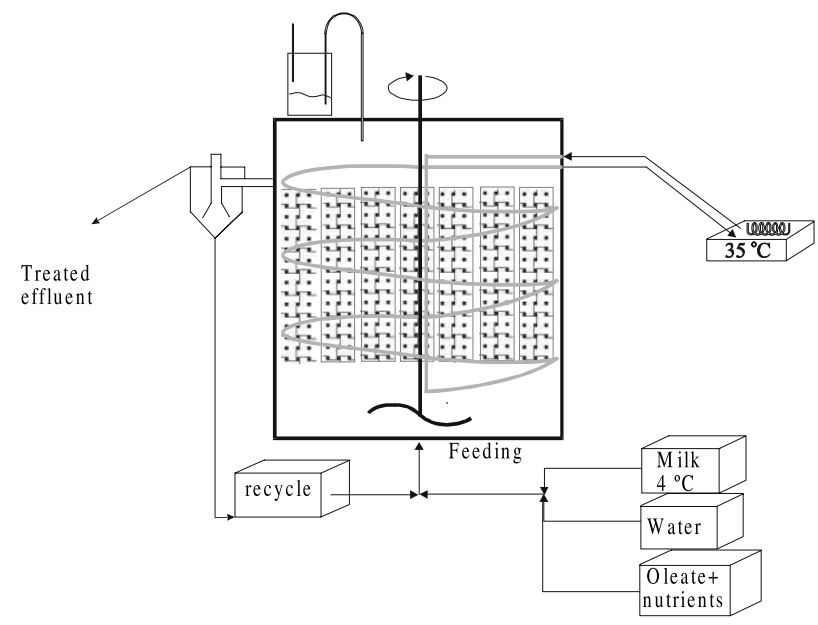

Fig. 1. Schematic representation of the experimental set-up.

\section{Materials and methods}

\subsection{Experimental set-up}

The anaerobic fixed-bed reactor configuration was described in detail elsewhere [9]. It allowed the regular withdrawal of some accumulated biomass with minimum operation disturbances. The experimental set-up is schematically presented in Fig. 1.

The reactor was a cylindrical tank constructed in PVC, with a diameter of $48 \mathrm{~cm}$ and a total volume of 86.81 . In the central section 27 mini-bioreactors, with a total volume of $989 \mathrm{~cm}^{3}$ each, were arranged in parallel constituting the support matrix. Fig. 2 represents the layout of the support section. The support medium consisted of PVC Raschig rings of $21 \mathrm{~mm}$ in size, and had a specific surface area of $230 \mathrm{~m}^{2} / \mathrm{m}^{3}$ and a porosity of $92.5 \%$. 86 rings were placed in each mini-bioreactor.

The effluent leaving the reactor entered a Plexiglas settler, and the settled biomass was subsequently recycled.

\subsection{Inoculum}

The reactor was inoculated with 151 of seed sludge containing $10 \mathrm{~g}$ of volatile suspended solids (VSS) per litre that was obtained from a local municipal sludge anaerobic digester.

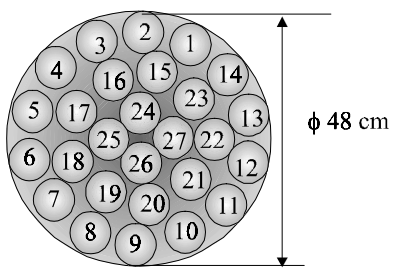

Fig. 2. Layout of the support section. 


\subsection{Substrate}

The reactor was fed with a synthetic dairy waste (made by dilution of skim milk with tap water) containing oleate, and was supplemented with macro and micronutrients, with the following composition: Macronutrients- $\mathrm{MgSO}_{4} \cdot 7 \mathrm{H}_{2} \mathrm{O}: 30.2 \mathrm{~g} / 1 ; \mathrm{KH}_{2} \mathrm{PO}_{4}: 28.3$ $\mathrm{g} / 1 ; \mathrm{KCl}: 45 \mathrm{~g} / 1$. Micronutrients [13]- $\mathrm{FeCl}_{2} \cdot 6 \mathrm{H}_{2} \mathrm{O}: 2 \mathrm{~g} / 1$; $\mathrm{H}_{3} \mathrm{BO}_{3}: 0.05 \mathrm{~g} / 1 ; \mathrm{ZnCl}_{2}: 0.05 \mathrm{~g} / 1 ; \mathrm{CuCl}_{2} \cdot 2 \mathrm{H}_{2} \mathrm{O}: 0.038 \mathrm{~g} / \mathrm{l} ;$ $\mathrm{MnCl}_{2} \cdot 4 \mathrm{H}_{2} \mathrm{O}: 0.5 \mathrm{~g} / 1 ;\left(\mathrm{NH}_{4}\right)_{6} \mathrm{Mo}_{7} \mathrm{O}_{24} \cdot 4 \mathrm{H}_{2} \mathrm{O}: 0.05 \mathrm{~g} / 1$; $\mathrm{AlCl}_{3} \cdot 6 \mathrm{H}_{2} \mathrm{O}: \quad 0.09 \mathrm{~g} / \mathrm{l} ; \quad \mathrm{CoCl}_{2} \cdot 6 \mathrm{H}_{2} \mathrm{O}: 2 \quad \mathrm{~g} / \mathrm{l} ;$ $\mathrm{NiCl}_{2} \cdot 6 \mathrm{H}_{2} \mathrm{O}: 0.092 \mathrm{~g} / 1 ; \quad \mathrm{Na}_{2} \mathrm{SeO}_{3} \cdot 5 \mathrm{H}_{2} \mathrm{O}: 0.164 \mathrm{~g} / 1$; EDTA: $1 \mathrm{~g} / 1$; Resazurin: $0.2 \mathrm{~g} / 1$; $\mathrm{HCl} 37 \%$ : $1 \mathrm{ml} / 1$. Macro and micronutrients were supplemented to the influent feed by addition of $0.6 \mathrm{~mL} / \mathrm{g}$ COD fed and 1 $\mathrm{mL} / 1$, respectively. To give suitable alkalinity $5 \mathrm{~g}$ $\mathrm{NaHCO}_{3}$ were added per litre of feeding. The substrate was stored at $4{ }^{\circ} \mathrm{C}$, to minimize acidification.

\subsection{Routine analysis}

Routine reactor performance was monitored by measuring influent chemical oxygen demand (COD), effluent soluble COD, influent flowrate, effluent VFA and effluent VSS.

COD and VSS were determined by Standard Methods [14]. VFA were determined by HPLC (Jasco, Japan) using a Chrompack column $\left(6.5 \times 30 \mathrm{~mm}^{2}\right)$; the mobile phase was sulphuric acid $(0.01 \mathrm{~N})$ at a flow rate of $0.7 \mathrm{ml} / \mathrm{min}$. The column temperature was set at $40{ }^{\circ} \mathrm{C}$ and the detection was made spectrophotometrically at a wavelength of $210 \mathrm{~nm}$. Methane content of biogas produced in batch experiments was measured by a Pye Unicam GCD gas chromatograph (Cambridge, England), using a Chrompack column Haysep Q (80$100 \mathrm{mesh}) . \mathrm{N}_{2}$ was used as carrier gas $(30 \mathrm{ml} / \mathrm{min})$ and the temperatures of injection port, column and flame ionisation detector were 120,40 and $130{ }^{\circ} \mathrm{C}$, respectively.

\subsection{Biomass characterization}

\subsubsection{Biomass separation and quantification}

In both experiments, the entrapped biomass was considered to be the fraction which was unattached to the support after being freely dispersed in a distilled water bath under circular movements with alternate sense for $1 \mathrm{~min}$. $\mathrm{N}_{2} / \mathrm{CO}_{2}$ (80:20), was continuously flushed to keep the anaerobic environment. After successive cycles of washing with anaerobic buffer and centrifugation at $6000 \mathrm{rpm}$ during $10 \mathrm{~min}$, this sludge was re-suspended in an anaerobic buffer and the total volume and volatile solids (VS) content were determined. Activity tests were performed with this fraction of biomass. Adhered biomass was removed from the support by using a $0.1 \mathrm{~N} \mathrm{NaOH}$ solution continuously stirred at $100 \mathrm{rpm}$ during $12 \mathrm{~h}$ at $37{ }^{\circ} \mathrm{C}$ followed by sonication [15]. Total volume and VSS were measured.

\subsubsection{Specific methanogenic activity and toxicity tests}

Methanogenic activity tests were performed using a pressure transducer technique [16,17]. The test involves the monitoring of the pressure increase developed in sealed vials fed with non-gaseous substrates or pressure decrease in vials previously pressurised with gaseous substrates $\left(\mathrm{H}_{2} / \mathrm{CO}_{2}\right)$. The non gaseous substrates were acetate, propionate, butyrate and ethanol. Strict anaerobic conditions were maintained. The hand held pressure transducer was capable of measuring a pressure increase or decrease of two bar $(0- \pm 202.6 \mathrm{kPa})$ over a range of $-200-+200 \mathrm{mV}$, with a minimum detectable variation of 0.005 bar. A sensing element consisting of a $2.5 \mathrm{~mm}$ square silicon chip with integral sensing diaphragm is connected to a digital panel meter module and the device is powered by a $7.5 \mathrm{~V}$ DC transformer. The basal medium used in the batch experiments, made up with distilled water, was composed of cysteine- $\mathrm{HCl}$ $(0.5 \mathrm{~g} / \mathrm{l})$ and sodium bicarbonate $(3 \mathrm{~g} / \mathrm{l})$, the $\mathrm{pH}$ was adjusted to 7.0-7.2 with $\mathrm{NaOH} 8 \mathrm{~N}$ and was prepared under strict anaerobic conditions. No calcium or tracenutrients were added. The same technique was used to characterize the methanogenic activity of the inoculum. The methanogenic activity values were corrected to the standard temperature and pressure conditions (STP), being expressed as $\mathrm{ml} \mathrm{CH}_{4(\mathrm{STP})} / \mathrm{g}$ VSS day.

Toxicity batch experiments were performed by adding $30 \mathrm{mM}$ of acetate and increasing oleate concentrations $(100,300,500,700$ and $900 \mathrm{mg} / 1)$ to the sludge, in batch vials. Working volume was $12.5 \mathrm{ml}$ and total volume $25 \mathrm{ml}$. Fifty percent inhibition concentration $\left(\mathrm{IC}_{50}\right)$ was defined as the oleate concentration that caused 50\% relative activity loss. All batch experiments were performed in triplicate assays.

\subsection{Operation mode}

During the start-up (Period I) the applied organic loading rate was gradually raised up to $6 \mathrm{Kg} \mathrm{COD} / \mathrm{m}^{3}$ day. The reactor was initially fed with skim milk followed by a mixture of skim milk (50\% COD) and sodium oleate $(50 \% \mathrm{COD})$. This proportion remained constant during all subsequent operation periods. After the start-up, the applied organic loading rate was increased 5-fold (30 Kg COD $/ \mathrm{m}^{3}$ day), by increasing the substrate concentration (simulation of an organic shock - Period II) or by decreasing the hydraulic retention time, HRT (simulation of a hydraulic shock - Period III). Both shocks lasted 4 days after what there was a return to pre-shock conditions (Table 1). The applied recirculation ratio was $\approx 1$, except in the case of the hydraulic shock, where the recirculation ratio was 0.2 . 
Table 1

Operating conditions during the trial period

\begin{tabular}{lcclll}
\hline Period & Time (days) & Concentration (mg COD $/ 1)$ & TRH (days) & Organic loading $\left(\mathrm{Kg}\right.$ COD $/ \mathrm{m}^{3}$ day) & Remarks \\
\hline I & $0-16$ & 2000 & 4 & 0.5 & 1 \\
& $16-34$ & 2000 & 2 & 2 & Introduction of oleate \\
& $34-54$ & 4000 & 2 & 4 & Pre-shock conditions \\
& $54-83$ & 4000 & 1 & 4 & Organic shock \\
II & $83-102$ & 4000 & 1 & 6 & Pre-shock conditions \\
& $102-140$ & 4000 & 0.667 & 30 & Hydraulic shock \\
III & $140-144$ & 20000 & 0.667 & 6 & Pre-shock conditions \\
& $144-230$ & 4000 & 0.667 & 30 & 6 \\
\end{tabular}

At different times along the shocks (Table 2), the reactor was opened and 2 of the mini-bioreactors, randomly selected, were removed and replaced by new similar ones, containing biomass obtained from the settler and recycling line. This procedure allowed for the withdrawal of biomass samples without changing the flow pattern throughout the reactor. The new inserted mini-bioreactors were not accounted for in the following samplings.

\section{Results and discussion}

\subsection{Performance}

Fig. 3 summarises the operating conditions applied and the performance during the trial period and Fig. 4 represents the time course of effluent VFA during the shock conditions.

The soluble COD removal efficiency was always higher than $90 \%$, except in shock situations, where it decreased from an average value of $94-30 \%$ in the case of the organic shock and to $73 \%$ in the hydraulic shock (Fig. 3(b)). The effluent VFA and VS levels increased in both shock situations, more markedly in the organic shock (Fig. 3(c) and (d), respectively). In both shocks accumulation of acetic, propionic and $n$-butyric acids was observed, whereas lactic, formic and iso-butyric acids appeared in small concentrations (Fig. 4). A faster response in terms of VFA production was observed in the case of the hydraulic shock, where the maximum values of VFA were detected $24 \mathrm{~h}$ after the beginning. In the case of the organic shock, the maximum VFA production was detected only $95 \mathrm{~h}$ after starting the shock. Furthermore levels of total VFA were more than 6-fold higher in the organic than in the hydraulic shock. Traces of valeric acid were detected, which is known to result from cell lysis [5].

In general the operational stability was more affected by the organic than by the hydraulic shock. A possible explanation is the partial precipitation of oleic acid by divalent ions, such as calcium or magnesium, by lowering their soluble (available) concentration through the production of a calcium and magnesium - oleate precipitate [18]. Addition of calcium was observed to reduce the toxicity of LCFA towards anaerobic bacteria [2].

Considering the contribution of tap water, milk and macronutrients to the calcium and magnesium content, the molar ratio oleate $/\left(\mathrm{Ca}^{2+}+\mathrm{Mg}^{2+}\right)$ was 1.49 and 2.35 , during the organic and the hydraulic shock, respectively. Therefore, in the latter case, even if all the calcium and magnesium ions had precipitated the oleate stoichiometrically, $0.5 \mathrm{~g} / 1(1.45 \mathrm{~g} \mathrm{COD} / 1)$ of oleate would still be available in the medium during the organic shock. Depending on the conditions of biomass structure and temperature this concentration can still be harmful to the anaerobic consortium [11]. Since in the hydraulic shock the molar ratio oleate $/\left(\mathrm{Ca}^{2+}+\mathrm{Mg}^{2+}\right)$ did not achieve the stoichiometric value of 2 , a total precipitation of the existing oleate would be theoretically possible, decreasing the effective oleate loading rate and consequently the applied loading rate.

\subsection{Biomass characterization}

\subsubsection{Distribution between adhered and entrapped fractions}

The relevant values of adhered and entrapped biomass, obtained during the shocks are presented in Table 3. The maximum and minimum values refer to values measured during the period of time of each shock, $95 \mathrm{~h}$. The long time value was determined in order to assess is the pre shock conditions were re-established or not. However it is difficult to attribute the changes exclusively to the shock effect because it is known that biomass is continuously accumulating even in pseudo steady state conditions for the liquid phase [19]. 
Table 2

Times of biomass withdrawal after starting the organic and the hydraulic shocks

Sampling time after starting the shocks (h)

\begin{tabular}{lllrrrrrrrrrrr}
\hline Organic shock & 0 & 0 & 4 & 11 & 14 & 25 & 33 & 49 & 63 & 80 & 95 & 145 & 900 \\
Hydraulic shock & 0 & & 5 & 9 & 24 & 51 & 74 & 95 & 167 & 341 & 900 & &
\end{tabular}
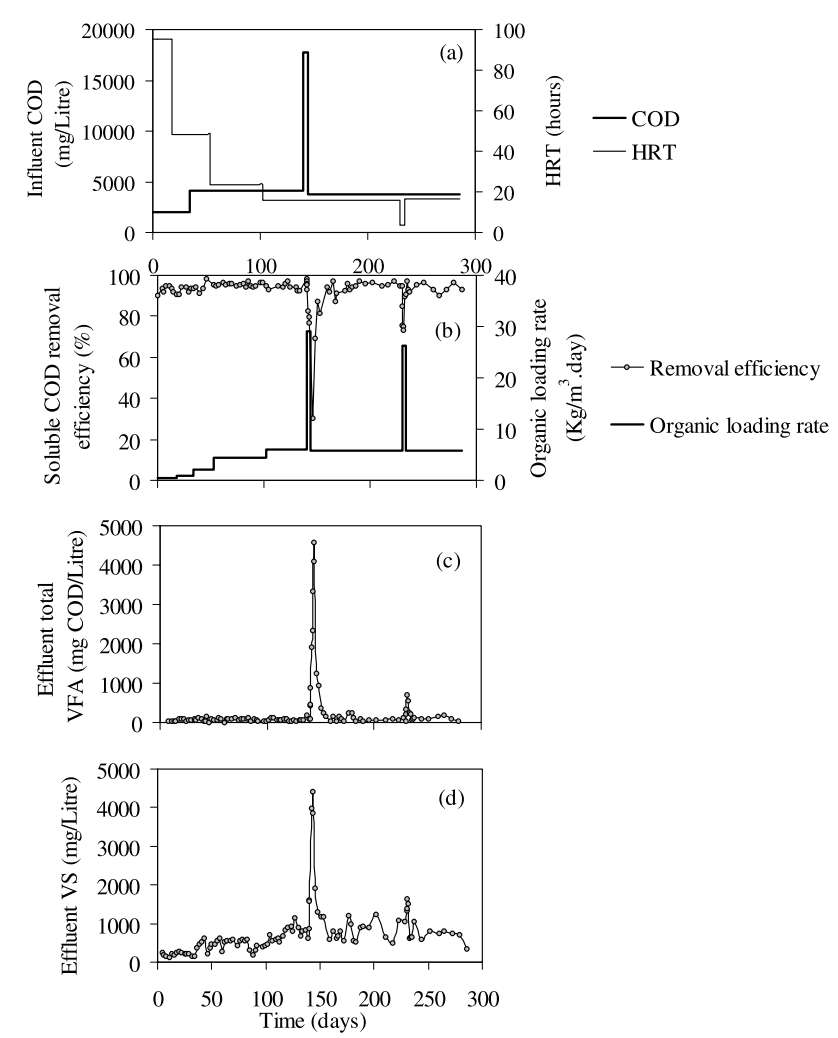

Fig. 3. Operating conditions and performance during the trial period. (a) Influent COD and HRT. (b) Soluble COD removal efficiency and applied organic loading rate. (c) Effluent VFA. (d) Effluent VSS.
In the organic shock adhered volatile solids (g VS/ $\mathrm{m}^{2}$ ) suffered high fluctuations. A maximum value, more than 2-fold the initial one, was obtained $80 \mathrm{~h}$ after starting the shock. The conditions of biofilm accumulation prevailed for quite a long time, since, $900 \mathrm{~h}$ after starting the shock the biofilm was still 4-fold more concentrated than at the beginning. However, $2160 \mathrm{~h}$ after starting the organic shock (time zero of the hydraulic shock) a return to the pre-shock values was detected. In the hydraulic shock a maximum value of adhered solids, $73 \%$ higher than the initial value, was detected $9 \mathrm{~h}$ after starting the shock. A long time after starting the hydraulic shock, the biofilm was still $57 \%$ thicker $(57 \%$ more VS) than the initial one. Fluctuation in the adhered biomass revealed that biofilm was changing with the applied conditions. A possible explanation is a shift from entrapped to adhered biomass or a migration of solids from the bottom towards the support section under shock loading conditions. Moreover VSS values account for biomass and possible adsorbed oleate.

The entrapped biomass was also more stable in the hydraulic shock than in the organic one. In the organic shock, a fast accumulation was detected, achieving 3.5 -fold the initial value, $4 \mathrm{~h}$ after starting the shock. 33 $\mathrm{h}$ after, the initial value was re-established and remained nearly constant for a long time after the shock (900 and $2160 \mathrm{~h}$ ). In the hydraulic shock a maximum of 2 -fold the initial value was detected $24 \mathrm{~h}$ after the shock, the initial value was re-established at the end of
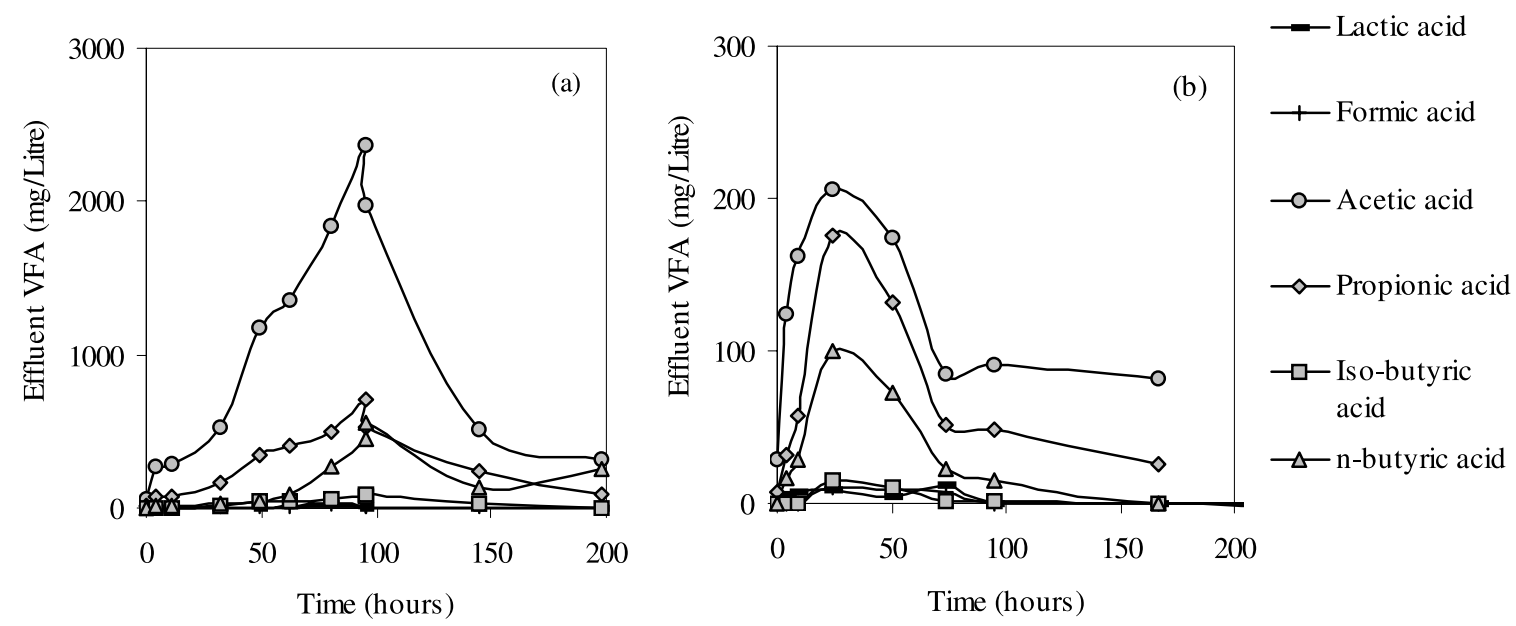

Fig. 4. Time course of VFA during (a) the organic shock and (b) the hydraulic shock and during the subsequent $\approx 100 \mathrm{~h}$. 

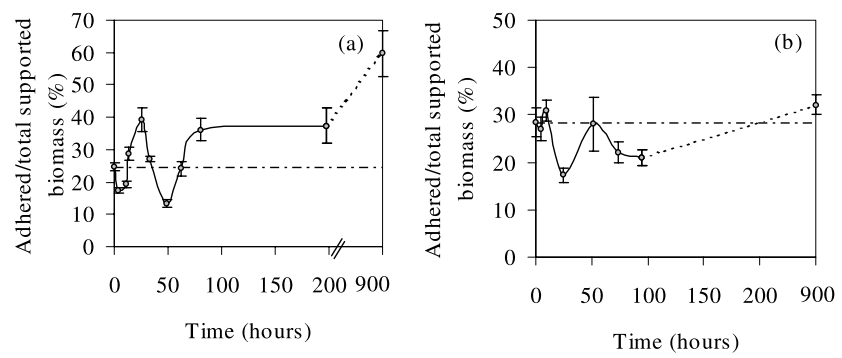

Fig. 5. Distribution of supported biomass during (a) the organic shock and (b) the hydraulic shock, and in the subsequent $900 \mathrm{~h}$. The dashed rectilinear line represents the initial stationary value.

Table 3

Distribution of biomass on the support matrix

$\begin{array}{ll}\begin{array}{l}\text { Adhered biomass } \\ \left(\mathrm{g} \mathrm{VSS} / \mathrm{m}^{2}\right)\end{array} & \begin{array}{l}\text { Entrapped biomass } \\ \text { (g VSS } / 1 \text { void })\end{array}\end{array}$

\begin{tabular}{lll}
\hline $\begin{array}{l}\text { Organic shock } \\
\text { Initial value }\end{array}$ & $2.2 \pm 0.1$ & $1.7 \pm 0.1$ \\
Minimum value & $1.8 \pm 0.1(49 \mathrm{~h})$ & $1.6 \pm 0.1(33 \mathrm{~h})$ \\
Maximum value & $5.4 \pm 0.4(80 \mathrm{~h})$ & $6.0 \pm 0.1(4 \mathrm{~h})$ \\
Long time value & $8.8 \pm 0.9(900 \mathrm{~h})$ & $1.5 \pm 0.2(900 \mathrm{~h})$ \\
& & \\
Hydraulic shock & & $1.6 \pm 0.2$ \\
Initial value & $2.6 \pm 0.3$ & $1.6 \pm 0.2(0,5$ and $95 \mathrm{~h})$ \\
Minimum value & $1.7 \pm 0.1(95 \mathrm{~h})$ & $3.4 \pm 0.2(24 \mathrm{~h})$ \\
Maximum value & $4.5 \pm 0.2(9 \mathrm{~h})$ & $3.0 \pm 0.1(900 \mathrm{~h})$ \\
Long time value & $4.1 \pm 0.2(900 \mathrm{~h})$ &
\end{tabular}

Adhered and entrapped biomass $\pm 95 \%$ confidence interval. Values in brackets represent the time, in hours, after starting each shock.

the shock ( $95 \mathrm{~h}$ ), but $900 \mathrm{~h}$ after, the entrapped biomass was 2-fold more concentrated than before the shock.

The biomass distribution in the support matrix is evidenced in Fig. 5, which represents the time course of the $\%$ adhered/total biomass during both shock conditions. The behaviour is similar in both shocks, but the effects are more marked in the organic shock. After the return to pre-shock conditions the adhered fraction increased, attaining maximum values of $59.8 \pm 7.1$ and $32.2 \pm 2.1 \%$ in the organic and hydraulic shock, respectively. In the former case this value is twice the initial one. In the hydraulic shock, the less pronounced variations observed suggest that the biofilm was, since the beginning, more resistant to the applied conditions.

\subsubsection{Specific methanogenic activity}

The entrapped fraction of the biomass samples removed at different periods during the shocks was characterized in terms of specific methanogenic activity with acetate, $\mathrm{H}_{2} / \mathrm{CO}_{2}$, propionate, butyrate and ethanol as substrates (Table 4). Concerning the methanogenic activity against propionate, butyrate and ethanol as substrates it should be said that, since these substrates are indirect methanogenic substrates, a valid measurement of the maximum specific methanogenic activity against these acids can only be obtained when the acetoclastic and hydrogenophilic activities are not rate-limiting [20]. In the present work this condition prevailed for almost all the samples. In general, there was an oscillating decreasing trend of the specific methanogenic activity until the end of both shock periods $(t=95 \mathrm{~h}$ after the beginning), followed by a recovery phase. The recovered values exceeded the initial ones, except for the syntrophic activity in the organic shock and the acetoclastic activity in the hydraulic shock.

Minimum methanogenic activities occurred simultaneously with the detection of maximum VFA levels in the organic shock, suggesting the inhibition of syntrophic and methanogenic bacteria by the high levels of VFA attained in that shock. $\mathrm{pH}$ was not lower than 6.5 during both shocks. $2160 \mathrm{~h}$ after the beginning of the organic shock, the methanogenic activities with propionate, butyrate, ethanol and $\mathrm{H}_{2} / \mathrm{CO}_{2}$ as substrates had not recovered their initial values, but the acetoclastic activity exceeded the initial values, indicating that this trophic group was not inhibited for such a long time

Table 4

Effect of the organic and hydraulic shocks on the methanogenic activity with acetate, propionate, butyrate, ethanol, and $\mathrm{H}_{2} / \mathrm{CO}_{2}$ as substrates $\pm 95 \%$ confidence interval

Methanogenic activity in the presence of: $\left(\mathrm{ml} \mathrm{CH}_{4} / \mathrm{g}\right.$ VSS day)

\begin{tabular}{llll}
\hline Acetate & Propionate & Butyrate & $\mathrm{H}_{2} / \mathrm{CO}_{2}$
\end{tabular}

\section{Organic shock}

Initial value

Minimum value

Maximum value

Long time value

Hydralic shock

Initial value

Minimum value

Maximum value

Long time value

$$
\begin{aligned}
409 & \pm 1 \\
52 & \pm 7(95 \mathrm{~h}) \\
487 & \pm 30(49 \mathrm{~h}) \\
476 & \pm 18(900 \mathrm{~h})
\end{aligned}
$$

$$
\begin{aligned}
& 573 \pm 59 \\
& 248 \pm 22(95 \mathrm{~h}) \\
& 573 \pm 59(0 \mathrm{~h}) \\
& 508 \pm 31(900 \mathrm{~h})
\end{aligned}
$$

$$
\begin{aligned}
184 & \pm 1 \\
0 & (95 \mathrm{~h}) \\
193 & \pm 5(4 \mathrm{~h})
\end{aligned}
$$$$
-
$$

$$
\begin{aligned}
60 & \pm 5 \\
7 & \pm 2(95 \mathrm{~h}) \\
102 & \pm 5(24 \mathrm{~h}) \\
98 & \pm 6(900 \mathrm{~h})
\end{aligned}
$$

$$
\begin{aligned}
148 & \pm 5 \\
0 & (80,95 \mathrm{~h}) \\
148 & \pm 5(0 \mathrm{~h})
\end{aligned}
$$$$
-
$$

$$
\begin{gathered}
65 \pm 6 \\
13 \pm 4(95 \mathrm{~h}) \\
109 \pm 10(24 \mathrm{~h}) \\
126 \pm 5(900 \mathrm{~h})
\end{gathered}
$$

$$
\begin{aligned}
& 217 \pm 9 \\
& 108 \pm 10(95 \mathrm{~h}) \\
& 316 \pm 17(14 \mathrm{~h})
\end{aligned}
$$$$
-
$$

$$
\begin{aligned}
& 146 \pm 17 \\
& 130 \pm 12(4 \mathrm{~h}) \\
& 311 \pm 60(24 \mathrm{~h}) \\
& 325 \pm 28(900 \mathrm{~h})
\end{aligned}
$$

$899 \pm 26$

$401 \pm 19$ (49 h)

$1000 \pm 40(14 \mathrm{~h})$

$110 \pm 1(900 \mathrm{~h})$

$493 \pm 45$

$479 \pm 4(74 \mathrm{~h})$

$690 \pm 48(95 \mathrm{~h})$

$892 \pm 30(900 \mathrm{~h})$

Values in brackets represent the time, in hours, after starting each shock. 
Table 5

Fifty percent inhibition concentration $\left(\mathrm{IC}_{50}\right)$ of sodium oleate towards acetoclastic bacteria $\pm 95 \%$ confidence interval

$\mathrm{IC}_{50}(\mathrm{mg}$ oleate/ $)$

Organic shock $(\mathrm{h})$

$t=0$

$120 \pm 30$

$t=840$

$20 \pm 5$

Hydraulic shock (h)

$t=0$

$140 \pm 30$

$t=892.5$

$215 \pm 25$ and recovered better than syntrophic or hydrogenophilic bacteria.

As a consequence of the more drastic conditions imposed, inhibition was more drastic during the organic shock, especially for the acetoclastic and syntrophic populations. This is indicated by the higher minimum values of activities detected in the hydraulic shock and by the complete recovery of all activities after the end of the shock.

The observed oscillation and recovery observed for the methanogenic activities during the shocks agree with previous works who reported that LCFA affect the acetogenic bacteria which are responsible for the $\beta$-oxidation, as well as the methanogenic bacteria that convert the products of $\beta$-oxidation (acetate and hydrogen) into methane $[2,3,21]$.

\subsubsection{Toxicity of sodium oleate towards acetoclastic bacteria}

The resistance of acetoclastic bacteria to oleic acid toxicity was compared before and after each shock, being the $\mathrm{IC}_{50}$ of sodium oleate towards acetoclastic bacteria presented in Table 5 .

The tolerance of acetoclastic bacteria to oleic acid toxicity decreased sharply with the application of the organic shock, but the application of the hydraulic shock increased this tolerance. Between both shocks there was also an increase in the toxicity limit from 20 to $140 \mathrm{mg}$ oleate $/ 1$.

The increase in the toxicity limits reflects an adaptation effect, which was induced by the steady state operation between the two shocks as well as by the hydraulic shock. This may be a consequence of the development of an acetogenic bacterial population capable of degrading the LCFA, preventing their accumulation to inhibitory concentrations.

\section{Conclusions}

(1) When treating a synthetic substrate containing $50 \%$ COD as oleic acid, deterioration of the digesters performance was more drastic and recovery was slower during and after an organic shock than in the case of a hydraulic shock.

(2) The less pronounced effects observed in the hydraulic shock and the quicker recovery may have resulted from a total precipitation of the oleate by the $\mathrm{Ca}^{2+}$ and $\mathrm{Mg}^{2+}$ cations, lowering the effective applied organic loading rate and permitting the development of an acetogenic population capable of degrading this LCFA.

(3) During the hydraulic shock the \%adhered/total retained biomass remained in the range of $17-32 \%$, whereas in the organic shock a wider range of variation was observed between 13 and $60 \%$.

(4) The specific methanogenic activity of the different trophic groups decreased until the end of the shocks and recovered thereafter. These effects were more marked in the organic shock and the recovery was slower in this situation.

(5) The activity values obtained $900 \mathrm{~h}$ after the shocks suggested the inhibition of the hydrogenophilic and syntrophic populations in the organic shock and a stimulation of these activities in the hydraulic shock.

(6) Acetoclastic bacteria were the trophic group that recovered better after the organic shock.

(7) Hydraulic shock induced an acclimatisation effect of acetoclastic bacteria towards oleic acid toxicity that was quantified by the increase in the toxicity limit, $\mathrm{IC}_{50}$, from $140 \pm 30$ to $215 \pm 25 \mathrm{mg}$ oleate $/ 1$.

\section{Acknowledgements}

The financial support from 'Fundação de Ciência e Tecnologia' through a MsC grant for Ana Júlia Cavaleiro is gratefully acknowledged. A special thank to Olga Pires for her contribution in the practical work.

\section{References}

[1] Weng C-N, Jeris JS. Biochemical mechanisms in the methane fermentation of glutamic and oleic acids. Wat Res 1976;10:918.

[2] Hanaki K, Matsuo T, Nagase M. Mechanisms of inhibition caused by long chain fatty acids in anaerobic digestion process. Biotechnol Bioeng 1981;23:1591-610.

[3] Rinzema A, Boone M, van Knippenberg K, Lettinga G. Bactericidal effect of long chain fatty acids in anaerobic digestion. Wat Environ Res 1994;66(1):40-9.

[4] Hwu C-S, Tseng S-K, Yuan C-Y, Kulik Z, Lettinga G. Biosorption of long-chain fatty acids in UASB treatment process. Wat Res 1998;32(5):1571-9.

[5] Grobicki A, Stuckey DC. Performance of the anaerobic baffled reactor under steady-state and shock loading conditions. Biotechnol Bioeng 1991;37:344-55.

[6] Chua H, Hu WF, Yu PHF, Cheung MWL. Responses of an anaerobic fixed-film reactor to hydraulic shock loadings. Biores Technol 1997;61(1):79-83. 
[7] Angelidaki I, Ahring BK. Effects of free long-chain fatty acids on thermophilic - anaerobic digestion. Appl Microbiol Biotechnol 1992;37:808-12.

[8] Anderson GK, Kasapgil B, Ince O. Comparison of porous and non-porous media in upflow anaerobic filters when treating dairy wastewater. Wat Res 1994;28(7):1619-24.

[9] Alves MM, Pereira MA, Bellouti M, Álvares Pereira MR, Mota Vieira JA, Novais JM, et al. A new method to study interactions between biomass and packing material in anaerobic filters. Biotechnol Tech 1998;12(4):277-83.

[10] Alves MM, Mota Vieira JA, Álvares Pereira RM, Pereira MA, Mota M. Effect of lipids and oleic acid on biomass development in anaerobic fixed-bed reactors. Part I: Biofilm growth and activity. Wat Res 2001a;35(1):255-63.

[11] Alves MM, Mota Vieira JA, Álvares Pereira RM, Pereira MA, Mota M. Effect of lipids and oleic acid on biomass development in anaerobic fixed-bed reactors. Part II: Oleic acid toxicity and biodegradability. Wat Res 2001b;35(1):264-70.

[12] Komatsu T, Hanaki K, Matsuo T. Prevention of lipid inhibition in anaerobic processes by introducing a two-phase system. Wat Sci Technol 1991;23(7-9):1189-200.

[13] Zehnder AJB, Huser BA, Brock TD, Wuhrmann K. Charaterization of an acetate-decarboxylating, non-hydrogen-oxidizing methane bacterium. Arch Microbiol 1980;124:1-11.
[14] APHA, AWWA, WPCF Standard Methods for the Examination of Water and Wastewater 1989. 17th Ed., Washington.

[15] Donlon, B., Acetogenesis, bacterial adhesion and lignocellulose conversion. Ph.D. Thesis 1992 University College, Galway, Ireland.

[16] Colleran E, Concannon F, Goldem T, Geoghegan F, Crumlish B, Killilea E, et al. Use of methanogenic activity tests to characterize anaerobic sludges, screen for anaerobic biodegradability and determine toxicity thresholds against individual anaerobic trophic groups and species. Wat Sci Technol 1992;25(7):31-40.

[17] Coates JD, Coughlan MF, Colleran E. Simple method for the measurement of the hydrogenotrophic methanogenic activity of anaerobic sludges. J Microbiol Meth 1996;26:237-46.

[18] Roy F, Albagnac G, Samain E. Influence of calcium addition on growth of highly purified sintrophic cultures degrading long chain fatty acids. Appl Environ Microbiol 1985;49:702-5.

[19] Hanaki K, Chatsanguthai S, Matsuo T. Characterization of accumulated biomass in anaerobic filter treating various types of substrates. Biores Technol 1994;47:275-82.

[20] Dolfing J, Bloemen WGBM. Activity measurements as a tool to characterize the microbial composition of methanogenic environments. J Microbiol Meth 1985;4:1-12.

[21] Hwu C-S, Lettinga G. Acute toxicity of oleate to acetate-utilizing methanogens in mesophilic and thermophilic anaerobic sludges. Enz Microb Technol 1997;21:297-301. 